\title{
The Effects of Sugar Addition and Degree of Roast on the Bioactive Compounds and Antioxidant Activity of Turkish-Style Coffee Brews
}

\author{
Emine Nakilcioğlu-Taş \\ Department of Food Engineering, Faculty of Engineering, Ege University, Izmir, TURKEY.
}

\begin{abstract}
Introduction: Coffee is one of the most widely consumed beverages by the people all around the world. This study was aimed to evaluate the effect of sugar addition, double effects of sugar addition and roasting degree on the polyphenol content, and antioxidant activity of Turkish-style coffee brews. Materials and Methods: The levels of three phenolic compounds (chlorogenic acid, caffeic acid, sinapic acid) and caffeine by reversed-phase high performance liquid chromatography (HPLC) method, as well as chromaticity parameters, absorbance value at $420 \mathrm{~nm}$, total phenolic and flavonoid content, antioxidant activities with two methods (DPPH and FRAP methods) were determined in different degree of roast Turkish-style coffee brews with sugar and without sugar. Results: It was found that antioxidant activity of Turkish-style coffee brews was increased while the phenolic content was decreased due to the degree of roasting process. Also, the addition of sugar into Turkish-style coffee brews at cooking stage caused decrease both in antioxidant activity and polyphenol content. Conclusion: The study indicated that light roasted coffee brews showed greater polyphenol content and medium roasted coffee brews had greater antioxidant capacity compared to other samples. Consumption of coffee brews without sugar provided the higher health benefits.
\end{abstract}

Key words: Antioxidant, Coffee, Degree of roast, Sugar addition, Phenolic compounds.

\section{INTRODUCTION}

Epidemiological studies have shown that a regular coffee consumption is directly related to the prevention of many chronic and degenerative diseases such as cardiovascular disorders, ${ }^{1}$ neurodegenerative disorders, ${ }^{2,3}$ obesity and diabetes, ${ }^{4,5,6,7}$ and even some types of cancers. ${ }^{8,9,10,11}$ It has been reported that these health benefits are not based on only single compound. They are due to the combined effects of coffee bioactive components, including phenolic compounds. ${ }^{12,13}$ The major class of polyphenols exist in coffee are hydroxycinnamic acids, ${ }^{14-20}$ mostly in esterified form with organic acids, sugars, and lipids. ${ }^{19,20}$ The major representative of hydroxycinnamic acids is also caffeic acid occurs in foods mainly as chlorogenic acid (5-caffeoylquinic acid, an ester of caffeic acid with quinic acid). In human diet, coffee is known as a major source of chlorogenic acid. ${ }^{14-20}$ Chlorogenic acid and derivatives have a number of beneficial health properties because of their antioxidant activity, ${ }^{21,22,23}$ However, one of the other biologically active compounds in coffee is caffeine. Caffeine, which has a bitter taste, is white crystalline xanthine alkaloid. It has several effects on body metabolism such as stimulating the central nervous system and increasing blood pressure in the short term. ${ }^{24,25}$

In the world, the most important agricultural harvest is coffee, which is second only after petroleum in terms of global trade activity and value. ${ }^{26,27}$ According to the International Coffee Organization, approximately 157 million bags of coffee are produced worldwide in 2015 and 2016
Submission Date: 05-09-2017; Revision Date: 08-11-2017; Accepted Date: 16-11-2017

DOI: 10.5530/ijper.52.3.53 Correspondence: Dr. Emine Nakilcioğlu-Taș, Food Engineering Department, Faculty of Engineering, Ege University, Bornova, 35100 Izmir TURKEY. Phone: +90 2323113007 E-mail: emine.nakilcioglu@ ege.edu.tr

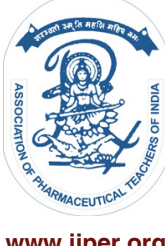

www.ijper.org 
years. ${ }^{28}$ The genus Coffea (Rubiaceae family) is possessed of over sixty different species and three of them; Coffea arabica L. (arabicas), Coffea robusta L. (robustas), and Coffea liberica L. have economical value. ${ }^{29,30}$ Especially Coffea arabica L. and Coffea robusta L. are produced commercially. ${ }^{27,31}$ Arabica variety is thought to be of superior quality due to the milder and more flavorful taste formed during roasting. ${ }^{27,32}$ The instant coffee industry use the Robusta coffee for the purpose of producing soluble coffee extracts. ${ }^{27,33}$ Turkish-style coffee brew is a sort of boiled coffee obtained by using the Turkish coffee preparation technique and Coffea Arabica L. ${ }^{34}$ The beans for Coffea Arabica L. are first roasted. The term of "roasted" covers light, medium, and dark degrees of roast, depending on its color. Specific changes occur in the chemical composition of roasted coffee. Depending on the degree of roast, the external color of the beans are changed (varying from light to dark brown), flavor is developed, the amount of dry matter loss is came about, some bioactive components is broken down and others are formed. ${ }^{35,36}$ Medium roasted coffee is generally used for preparation of Turkish-style coffee brew because it is appealing to the taste buds of Turkish people. After roasting, beans are grounded or pounded to obtain the finest possible powder, and the powder has finer particles than used coffee in other preparation methods. The coffee bean powder obtained can be named as "Turkish coffee". Turkish coffee is mixed with cold water and boiled in a special type of narrow topped small pot called a "cezve" with sugar or not sugar. It is served hot in a cup. ${ }^{34,37}$ Turkish-style coffee brew is a very famous drink and consumed widely by enjoying with the same preparation technique in the Balkan and Middle East countries. ${ }^{38}$

In the literature, several studies were found about the antioxidant activity and/or polyphenolic content of coffees roasted at different temperatures and times. ${ }^{30,39,41-45}$ Only one of them examined the polyphenols and differences in antioxidant content Turkish-style coffee brews. ${ }^{30}$ Yet, there is no study, which determines the effect of addition of sugar into the coffee or Turkish-style coffee brew on the polyphenolic content and antioxidant activity at the cooking processes. Also, no literature found clarifying the double effects of addition of sugar in the Turkish-style coffee brew and different degree of roast of Turkish coffee on the polyphenolic content and antioxidant activity of coffee, either. This study will be the first of its kind for these reasons.

Besides Turkish-style coffee brews being a quite popular drink, there are also many positive effects on human health. The degree of roast or formulation change can modify the phenolic profile of Turkish-style coffee brew, and so, physiological effects it exhibits on human may change as well. The aim of this study is to investigate the influence of degree of roast and adding sugar on phenolic and antioxidant properties of Turkish-style coffee brew (TCB).

\section{MATERIALS AND METHODS \\ MATERIALS}

\section{Samples}

Four different Turkish coffee samples (green (crude), light roasted, medium roasted and dark roasted coffee) produced from the same coffee beans were purchased from local coffee shop (İlyas Gönen Coffee (Izmir, Turkey)). All of the analyses were made from green and roasted Arabica coffee beans that were roasted to three roasting degrees $\left(\mathrm{L}^{*}\right.$-values $\left.37.28,28.50,15.92\right)$ at $200^{\circ} \mathrm{C}$ using a table-top roaster and ground very finely $(<300 \mu \mathrm{m})$ with a Turkish coffee grinder. The moisture contents of analyzed samples were $7.99 \%$ (green roasted Turkish coffee), $4.99 \%$ (light roasted Turkish coffee), $2.52 \%$ (medium roasted Turkish coffee) and $2.36 \%$ (dark roasted Turkish coffee).

\section{Brewing}

All of the coffee brews were prepared with a Turkish coffee machine (Arçelik, Istanbul, Turkey), because cooking are performed with a machine at equal temperature and time. According to the standardization of brewing procedure, ground coffee $(5 \mathrm{~g})$ and ultra-pure distilled water $(65 \mathrm{~mL})$ were heated in a Turkish coffee machine. The sugar $(8 \mathrm{~g})$ was added into some samples at cooking stage. Then they were cooled to $25^{\circ} \mathrm{C}$ and finally filtered through the Whatman no. 3 filter paper (Figure 1). The green, light roasted, medium roasted,

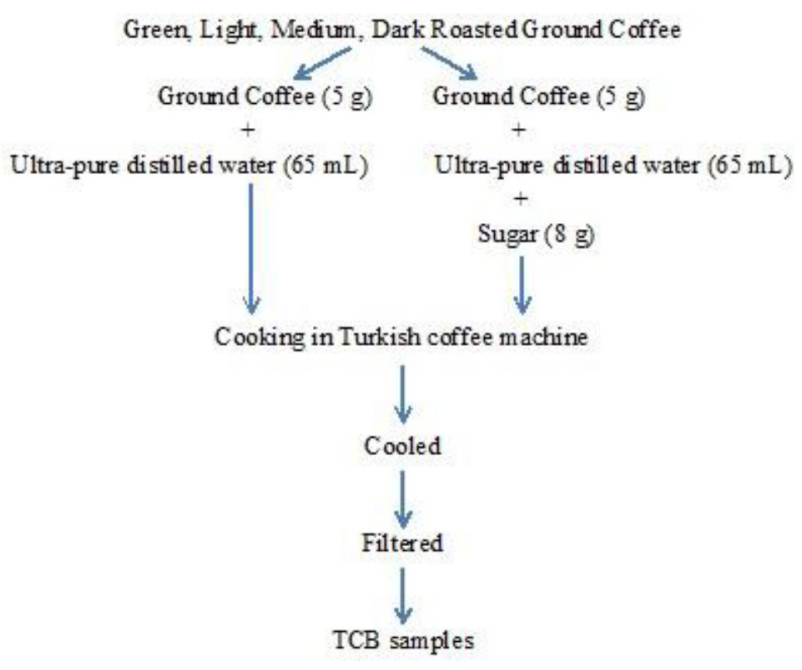

Figure 1: The brewing procedure of TCBs. 
dark roasted TCBs with no sugar were named as TCB1, TCB2, TCB3, TCB4 and ones with sugar were also named as TCB5, TCB6, TCB7, TCB8, respectively.

\section{METHODS}

\section{Color Measurement in TCBs}

Color analysis was carried out utilizing the Hunter colorimeter (CFLX 45-2 Model Colorimeter, Hunter Lab, Reston, VA) with direct reading of the $\mathrm{L}^{*}(0$ darkness, 100 brightness), $a^{*}$ (+ redness, - greenness) and $b^{*}$ (+ yellowness, - blueness) CIELAB scale parameters and calibrated using a standard black reflector plate. The $L^{*}, a^{*}$ and $b^{*}$ values were converted to different functions of color as the total color difference $\left(\Delta \mathrm{E}^{*}\right)$, chroma $\left(\mathrm{C}^{*}\right)$ and hue angle $\left(\mathrm{h}^{\circ}\right)$ values by using following the equations:

$$
\begin{aligned}
& \mathrm{C}^{*}=\sqrt{\left(\mathrm{a}^{*}\right)^{2}+\left(\mathrm{b}^{*}\right)^{2}} \\
& \Delta \mathrm{E}^{*}=\sqrt{\left(\Delta \mathrm{L}^{*}\right)^{2}+\left(\Delta \mathrm{a}^{*}\right)^{2}+\left(\Delta \mathrm{b}^{*}\right)^{2}} \\
& \mathrm{~h}^{0}=\tan ^{-1}\left(\frac{\mathrm{b} *}{\mathrm{a}^{*}}\right) \\
& \Delta \mathrm{L}^{*}=\mathrm{L}_{0} *-\mathrm{L}^{*} \\
& \Delta \mathrm{a}^{*}=\mathrm{a}_{0} *-\mathrm{a} * \\
& \Delta \mathrm{b}^{*}=\mathrm{b}_{0} *-\mathrm{b}^{*}
\end{aligned}
$$

where $\mathrm{L}_{0} *, \mathrm{a}_{0}{ }^{*}, \mathrm{~b}_{0} *$ were initial values of TCB1 or TCB5; $\mathrm{L}^{*}, \mathrm{a}^{*}, \mathrm{~b}^{*}$ were the values of light/medium/dark roasted coffee brews with or without sugar.

\section{Browning Intensity in TCBs (Abs 420 nm)}

$100 \mu \mathrm{l}$ of coffee brews were diluted up to $2 \mathrm{~mL}$ with ultra-pure distilled water, and then, browning intensity was determined by measuring the absorbance of samples at $420 \mathrm{~nm}$ in a $1.5 \mathrm{~mL}$ capacity cuvette $(1 \mathrm{~cm}$ length) with a spectrophotometer (Optizen Pop, Mecasys Co., Ltd., Korea). ${ }^{42}$

\section{Determination of Total Phenolic Content in TCBs}

The total phenolic content of coffee brews was quantified according to the method described by Singleton and Rossi (1965), ${ }^{46}$ and Li et al. (2006) ${ }^{47}$ with some modifications. $0.5 \mathrm{~mL}$ of the diluted coffee brew was mixed with $2.5 \mathrm{~mL}$ of $0.2 \mathrm{~N}$ Folin-Ciocalteu phenol reagent and $2 \mathrm{~mL}$ of $7.5 \%$ sodium carbonate. The mixture was left to stand at dark and room temperature for $30 \mathrm{~min}$ before measuring the absorbance of the solution at $760 \mathrm{~nm}$, using a spectrophotometer. The results were expressed as $\mathrm{mg}$ of gallic acid equivalents (GAE) per $100 \mathrm{~mL}$ for coffee brews ( $\left.\mathrm{y}=0.0084 \mathrm{x}+0.0049, \mathrm{R}^{2}=0.9988\right)$.

\section{Determination of Total Flavonoid Content in TCBs}

The total flavonoid content of coffee brews was determined using the method of Heimler et al. (2005). ${ }^{48} 250 \mu \mathrm{L}$ of coffee brew and $1.25 \mathrm{~mL}$ of distilled water were mixed with $75 \mu \mathrm{L}$ of $5 \% \mathrm{NaNO}_{2}$ solution. The mixture was stood for 6 min at dark and room temperature. Then, $150 \mu \mathrm{L}$ of $10 \% \mathrm{AlCl}_{3} \cdot 6 \mathrm{H}_{2} \mathrm{O}$ was added. After it was incubated for $5 \mathrm{~min}$ at dark and room temperature, $0.5 \mathrm{ml}$ of $0.1 \mathrm{M} \mathrm{NaOH}$ solution and $275 \mu \mathrm{L}$ of distilled water were added into the mixture. Thus, the volume of mixture is reached to $2.5 \mathrm{~mL}$. The absorbance was measured at $510 \mathrm{~nm}$ using a spectrophotometer, immediately. Total flavonoid content was expressed as $\mathrm{mg}$ of $(+)$-catechin $((+)-C E)$ equivalents per $100 \mathrm{~mL}$ for coffee brews $\left(\mathrm{y}=0.0036 \mathrm{x}-0.0069, \mathrm{R}^{2}=0.9963\right)$.

\section{Determination of Antioxidant Activity by the DPPH Radical Scavenging Method in TCBs}

Detecting of the scavenging effect on 2,2-diphenil1-picrylhydrazyl (DPPH) free radical in coffee brews was performed as following the methods of $\mathrm{Chu}$ et al. $(2000)^{49}$ and Cheung et al. (2003) $)^{50}$ with some modifications. $0.5 \mathrm{ml}$ of $0.1 \mathrm{mM}$ DPPH radical prepared in methanol was mixed with $1 \mathrm{ml}$ of coffee brews by using vortex. When the control was also prepared, coffee brew was replaced by methanol. After mixing, the absorbance (Abs) was measured immediately at $520 \mathrm{~nm}$ with a spectrophotometer. The scavenging activity (\%) of DPPH radicals for each coffee brews was calculated using the following formula:

The scavenging activity $\%=\frac{\left(\mathrm{A}_{\text {control }}-\mathrm{A}_{\text {sample }}\right)}{\mathrm{A}_{\text {control }}} \times 100$

\section{Determination of Antioxidant Activity by the FRAP Radical Scavenging Method in TCBs}

The ferric reducing antioxidant power (FRAP) assay was applied to estimate the antioxidant capacity of coffee brews according to the methods of Guo et al. $(2003)^{51}$ and $\mathrm{Xu}$ et al. $(2004)^{52}$ with some modifications. The solution of the FRAP reagent was prepared via addition, at 1:1:10 (v/v/v), of $10 \mathrm{mmol} / \mathrm{L} \mathrm{2,4,6-Tri(2-}$ pyridyl)-s-triazine (TPTZ) solution in $40 \mathrm{mmol} / \mathrm{L} \mathrm{HCL}$, $20 \mathrm{mmol} / \mathrm{L} \mathrm{FeCI}_{3}$ solution and $0.3 \mathrm{~mol} / \mathrm{L} \mathrm{pH} 3.6$ acetate buffers. FRAP solution was warmed to $37^{\circ} \mathrm{C}$ and then $40 \mu \mathrm{L}$ of the diluted coffee brew was mixed to $1.8 \mathrm{~mL}$ of FRAP solution and 200 of $\mu \mathrm{L}$ distilled water. The mixture was incubated at $37^{\circ} \mathrm{C}$ for $30 \mathrm{~min}$. After 
the absorbance was determined at $593 \mathrm{~nm}$ using a spectrophotometer, the calculated values were expressed as $\mathrm{mg}$ of reduced iron equivalents per $100 \mathrm{~mL}$, based on a $\mathrm{FeSO}_{4} 7 \mathrm{H}_{2} \mathrm{O}$ calibration curve $(\mathrm{y}=0.2448 \mathrm{x}+0.034$, $\left.\mathrm{R}^{2}=0.9884\right)$

\section{The Determination of Phenolic Compounds and Caffeine in TCBs by HPLC}

\section{HPLC Analysis}

The protocol of analysis was based on the conditions used by Belguidoum et al. (2014). ${ }^{53}$ In this context, an Agilent 1200 LC system (Agilent, Santa Clara, CA) with a diode array detector (DAD), a gradient elution pump and vacuum degasser, an auto sampler system, and a thermos-stated column compartment were used. ACE $5 \mathrm{C}_{18} 5 \mu \mathrm{m}, 100 \AA, 250 \times 4.6 \mathrm{~mm}$ column (Advanced Chromatography Technologies Ltd, UK) was utilized for separation. 1\% phosphoric acid in water (solvent A) and $1 \%$ phosphoric acid in acetonitrile (solvent B) were applied as a binary gradient elution. The gradient program began at 30\% B, then increased until 50\% B in the course of $8 \mathrm{~min}$ and held for $2 \mathrm{~min}$. Re-equilibration time was $10 \mathrm{~min}$ at $30 \% \mathrm{~B}$. A constant flow rate of $1 \mathrm{~mL} / \mathrm{min}$ was used with an injection volume of $20 \mu \mathrm{L}$. The caffeine and cinnamic acid were monitored at $280 \mathrm{~nm}$, while caffeic acid, ferulic acid, sinapic acid, and chlorogenic acid were monitored at $324 \mathrm{~nm}$. The DAD was adjusted to collect spectral data over the range 190-400 nm. In coffee brews chlorogenic acid, caffeic acid, sinapic acid, and caffeine were identified qualitatively by comparing retention times, spectra of standards and using standard addition technique, and quantitatively by applying the external standards method $(\mathrm{y}=1.7106 \mathrm{x}-$ $52.6952, \mathrm{R}^{2}=0.9982$ for chlorogenic acid, $\mathrm{y}=1.8721 \mathrm{x}$ $+85.6517, \mathrm{R}^{2}=0.9964$ for caffeic acid, $\mathrm{y}=2.4469 \mathrm{x}$ $145.4581, \mathrm{R} 2=0.9970$ for sinapic acid and $\mathrm{y}=1.4979 \mathrm{x}$ $-27.9205, R^{2}=0.9999$ for caffeine).

\section{Analytical Method Validation}

The limit of detection (LOD) and limit of quantification (LOQ) were determined considering as 3:1 and 10:1 peak to noise ratio, respectively. ${ }^{54}$ The LOD ranged from 0.01 to $0.02 \mathrm{mg} / \mathrm{L}$, when the LOQ ranged from 0.03 to $0.05 \mathrm{mg} / \mathrm{L}$ (Table 1 ). The recovery capacities of the method were evaluated with adding the original concentrations defined in samples of standard phenolic compound and caffeine in coffee brews with sugar or without sugar. The values of recovery were greater than $99 \%$ for all compounds, except sinapic acid (Table 1).

Additionally, five different standard concentrations were used for forming calibration curves and range of their concentrations was between 3.13 to $62.50 \mathrm{mg} / \mathrm{L}$, approximately. Correlation coefficients in calibration curve were greater than 0.99 for all standards of phenolic compound and caffeine.

\section{Statistical Analysis}

All experiments were carried out triplicate during this study and results were expressed as means \pm standard deviations. Statistical analyses were realized with the SPSS v.20.0 software package. One-way analysis of variance (ANOVA) was performed to determine the significant difference in all analysis between the green, light, medium, and dark roasted Turkish-style coffee brews. Duncan's multiple range tests were used to determine the significant difference of the data sets of the green and different roasting degree Turkish-style coffee brews. Pearson correlation test was utilized for assessing correlations among variables. Paired sample t-test was also carried out for evaluating the significant difference between Turkish-style coffee brews with/without sugar in all analysis. Level of significance was accepted as 95\% in all statistical analysis.

\section{RESULTS AND DISCUSSION \\ Influence of Degree of Roast and Sugar Addition on Color and Browning Intensity of TCBs.}

In heat-treated foods, like coffee, one of the most visual changes is brown color development during the process. ${ }^{42}$ In this study, the color of different TCBs was determined by means of the CIELab parameters $\left(\mathrm{L}^{*}, \mathrm{a}^{*}, \mathrm{~b}^{*}\right.$ and also $\Delta \mathrm{E}^{*}, \mathrm{C}^{*}$ and $\mathrm{h}^{\circ}$ as chromaticity parameters) and the Absorbance at 420nm (Table 2).

\begin{tabular}{|c|c|c|c|c|c|c|c|}
\hline \multirow[t]{2}{*}{ Compounds } & \multirow{2}{*}{$\begin{array}{l}\text { Retention } \\
\text { time (RT) }\end{array}$} & LOD & LOQ & \multirow{2}{*}{$\begin{array}{l}\text { Regression equation for } \\
\text { calibration curve }\end{array}$} & \multirow[t]{2}{*}{$\mathbf{R}^{2}$} & \multirow{2}{*}{$\begin{array}{c}\begin{array}{c}\text { Recovery } \\
\text { for TCB3 }\end{array} \\
{[\%]}\end{array}$} & \multirow{2}{*}{$\begin{array}{c}\begin{array}{c}\text { Recovery } \\
\text { for TCB7 }\end{array} \\
{[\%]}\end{array}$} \\
\hline & & [mg/L] & [mg/L] & & & & \\
\hline $\begin{array}{l}\text { Chlorogenic } \\
\text { acid }\end{array}$ & 2.949 & 0.01 & 0.04 & $y=1.71058036 x-52.695182$ & 0.9982 & 99.32 & 99.01 \\
\hline Caffeine & 3.478 & 0.02 & 0.05 & $y=1.49787555 x-27.920499$ & 0.9999 & 101.46 & 100.68 \\
\hline Caffeic acid & 3.815 & 0.01 & 0.03 & $y=1.87307244 x+85.65169$ & 0.9964 & 98.06 & 99.27 \\
\hline Sinapic acid & 5.097 & 0.01 & 0.04 & $y=2.44687187 x-145.45809$ & 0.9970 & 97.10 & 97.39 \\
\hline
\end{tabular}




\begin{tabular}{|c|c|c|c|c|c|c|c|}
\hline \multirow[b]{2}{*}{ Samples } & \multirow{2}{*}{$\begin{array}{c}\text { Browning } \\
\text { intensity } \\
\text { (Absorbance } \\
\text { at } 420 \mathrm{~nm} \text { ) }\end{array}$} & \multicolumn{6}{|c|}{ Chromaticity parameters } \\
\hline & & $L^{*}$ & $a^{*}$ & $\mathbf{b}^{*}$ & $\mathbf{C}^{*}$ & $h^{\circ}$ & $\Delta \mathrm{E}^{*}$ \\
\hline TCB1 & $0.036 \pm 0.0001 \mathrm{~g}$ & $0.96 \pm 0.03 e$ & $-0.40 \pm 0.08 g$ & $0.70 \pm 0.07 \mathrm{e}$ & $0.81 \pm 0.09 \mathrm{e}$ & $60.19 \pm 2.89 a$ & - \\
\hline TCB2 & $0.391 \pm 0.0005 d$ & $11.26 \pm 0.11 a$ & $12.17 \pm 0.16 a$ & $16.61 \pm 0.39 a$ & $20.59 \pm 0.24 a$ & $53.77 \pm 0.96 b$ & $22.75 \pm 0.25 a$ \\
\hline TCB3 & $0.437 \pm 0.0005 b$ & $1.93 \pm 0.10 c$ & $3.36 \pm 0.24 d$ & $2.84 \pm 0.20 c$ & $4.40 \pm 0.26 c$ & $40.25 \pm 2.18 d$ & $4.44 \pm 0.26 c$ \\
\hline TCB4 & $0.481 \pm 0.0012 a$ & $1.31 \pm 0.10 \mathrm{~d}$ & $1.62 \pm 0.12 \mathrm{e}$ & $1.79 \pm 0.15 d$ & $2.42 \pm 0.17 d$ & $47.85 \pm 2.18 \mathrm{c}$ & $2.33 \pm 0.16 \mathrm{~d}$ \\
\hline TCB5 & $0.043 \pm 0.0005 f$ & $1.05 \pm 0.05 \mathrm{e}$ & $-0.48 \pm 0.06 g$ & $0.08 \pm 0.01 f$ & $0.47 \pm 0.06 \mathrm{e}$ & $9.93 \pm 1.80 \mathrm{e}$ & - \\
\hline TCB6 & $0.345 \pm 0.0004 \mathrm{e}$ & $8.79 \pm 0.58 b$ & $11.78 \pm 0.06 b$ & $13.28 \pm 0.89 b$ & $17.75 \pm 0.68 b$ & $48.38 \pm 1.79 c$ & $19.61 \pm 0.84 b$ \\
\hline TCB7 & $0.414 \pm 0.0001 \mathrm{c}$ & $1.86 \pm 0.06 c$ & $3.58 \pm 0.13 c$ & $2.74 \pm 0.10 c$ & $4.50 \pm 0.16 c$ & $37.42 \pm 0.47 d$ & $4.91 \pm 0.16 c$ \\
\hline TCB8 & $0.484 \pm 0.0003 a$ & $1.35 \pm 0.10 \mathrm{~d}$ & $1.33 \pm 0.18 f$ & $1.90 \pm 0.18 d$ & $2.33 \pm 0.14 d$ & $55.06 \pm 5.29 b$ & $2.59 \pm 0.15 d$ \\
\hline
\end{tabular}

a Values are given as "mean \pm standard deviation". Different matching letters in a column express significant differences according to Duncan test ( $p<0.05$ ).

Differences in roasted degree of TCBs had significant effects $(p<0.05)$ on all of chromaticity parameters. Green Turkish-style coffee brews (TCB1 and TCB5) had the lowest $\mathrm{L}^{*}, \mathrm{a}^{*}, \mathrm{C}^{*}$ values and the lowest $\mathrm{b}^{*}$ and $\mathrm{h}^{\circ}$ values belonged to TCB5 sample statistically $(p<0.05)$. While all chromaticity parameters of TCB2 were found to be significantly higher than other samples, $h^{\circ}$ value was the highest in TCB1 and difference was found statistically important $(p<0.05)$. With increasing the roasting degree, a color was obtained darker, paler with yellow and red shades in TCBs. Similar changes in color and chromaticity parameters with roasting were also observed by Sacchetti et al. (2009) ${ }^{40}$ and Ludwig et al. (2013)..$^{55}$ The highest total color difference of TCBs was found in TCB2; the lowest amount was in TCB4 and TCB8 $(p<0.05)$ in accordance with the results of Liang et al. (2016) ${ }^{56}$ and statistically important difference was determined as well. No statistically significant difference was observed between the chromaticity parameters except the $h^{\circ}$ value as a result of sugar addition to TCBs $(p<0.05)$.

The $420 \mathrm{~nm}$ wavelength has been used to assess the color intensity of browning reaction mixtures affecting the palatability of heat processed foods and beverage. ${ }^{57,58}$ The impact of sugar addition and the degree of roast in TCBs significantly affected absorbance at $420 \mathrm{~nm}$ $(p<0.05)$. When TCBs were evaluated in terms of roasting degree, the lowest absorbance at $420 \mathrm{~nm}$ was found in TCB1 and also the samples of TCB4, TCB8 exhibited the highest absorbance at $420 \mathrm{~nm}$ statistically $(p<0.05)$. Generally, these results are in agreement with the reports of Ludwig et al. (2013) $)^{55}$ and Liang et al. (2016). ${ }^{56}$

The most well-known Maillard reaction products are melanoids generated during the roasting process. ${ }^{56,59}$ They are one of the compounds responsible for the brown color of coffee. The sugar (retro) aldolization/ dehydratation and carbohydrate condensation products are also known as many other brown-colored products in roasted coffee. ${ }^{42,60,61}$ These compounds are the cause of increasing in brown color as the roasting degree increases. For this reason, the absorbance value at $420 \mathrm{~nm}$ of TCBs increased, as the roasting degree of coffee increased. Also, it is found that addition of sugar to TCBs formed a statistically significant difference in the absorbance at $420 \mathrm{~nm}(p<0.05)$. When sugar and Turkish-style coffee brew is mixed and stirred, firstly the concentrated liquid is obtained. Then, the mixture becomes lighter with increasing temperature and ongoing stirring. The small bubbles are formed. So, the volume is increased. The same color is diffused across to a larger area. Therefore, the color got diluted and its intensity started to disappear. It is concluded that the color of TCBs with sugar is lighter than the ones without sugar. According to a study of Al-Wahab (2009), ${ }^{62}$ the color difference between coffee brews with sugar and no sugar might be due to the sticky effect of sugar on the staining of coffee.

\section{Total Phenolic Content and Total Flavonoid Content of TCBs}

The methods used for the determination of the polyphenol content are based on a redox reaction. The Folin-Ciocalteu method and the aluminum chloride colorimetric method can be considered as general methods of total polyphenol and flavonoid content determination, respectively. ${ }^{63,64}$ The total polyphenol content and flavonoid content of TCBs are tabulated in Table 3. While the lowest polyphenol and flavonoid content found in the sample of TCB8 (209.49 $\pm 3.04 \mathrm{mg}$ GAE per $100 \mathrm{~mL}$ TCB and $15.50 \pm 1.11 \mathrm{mg}$ GAE per $100 \mathrm{~mL}$ TCB) relative to other coffee samples that had 
different roasting degrees, TCB2 had statistically the highest amount of polyphenols and flavonoids content $(337.23 \pm 3.63 \mathrm{mg}$ GAE per $100 \mathrm{~mL}$ TCB and 164.67 $\pm 2.50 \mathrm{mg}$ GAE per $100 \mathrm{~mL}$ TCB) among the roasted TCBs $(p<0.05)$. According to the statistical analysis of variance, the differences found among polyphenol and flavonoid content in the samples were statistically significant $(p<0.05)$. The Maillard reaction products formed during roasting process, reacted to Folin-Ciocalteu reagent and contributed to the increase in total phenolic compounds measured by Folin-Ciocalteu assay. ${ }^{40-67}$ At the beginning of the thermal process, a smaller loss of polyphenols and more Maillard reaction products formation occurs for light roasted TCBs compared to green TCBs (Table 3). For this reason, total polyphenol content measured in samples exhibited a slight increase with the roasting process, and then, it was determined that the phenolic and flavonoid content with roasting process showed an inverse proportional change. The reason for the lower levels of polyphenols compared to Maillard product formation in roasted coffee can be polymerization, autoxidation or degradation of phenolic compounds during roasting. ${ }^{65,68}$ In this study, the change of total phenolic and flavonoid determined in TCBs with different roasting degrees correlate with the results of Cämmerer and Kroh (2006); ${ }^{65}$ Górnaś et al. (2016); ${ }^{45}$ Ludwig et al. $(2013)^{55}$ and Sacchetti et al. (2009)..$^{40}$

In comparison to TCBs prepared only with water and the addition of sugar, sugar significantly decreased total phenolic and flavonoid content of TCBs $(p<0.05)$. This result is similar with the results obtained by Sharma et al. $(2008)^{69}$ whom reported that the total polyphenol content and antioxidant activity of tea samples are found to be higher in black tea sample compared to tea with milk, tea with sugar, and tea with sugar and milk samples. Similarly, Lončarić et al. (2016) ${ }^{70}$ reported that a freeze-dried sour cherry puree with addition of sucrose had lower content of total phenolic, flavonoid and anthocyanin compared to control and other samples with addition of maltose and trehalose. Actually, results could be explicated by the importance of water content, its interactions between compounds in food matrix, and behavior of disaccharides in water. Water can be treated as the reactant rather than as the solvent at lower water activities (0.05-0.43), and this situation results in the increase of degradation rate of the polyphenols. Higher water activities are inducing conditions for diffusionlimited reactions. Therefore, combined effect of enzymatic activity, oxidation, and molecular mobility, which are the results of more available water are resulting degradation of sensitive compounds. ${ }^{70,71}$ Finally, poly- phenol degradation occurred due to the water content of TCBs.

\section{Antioxidant Activity by the DPPH and FRAP Radical Scavenging Method of TCBs.}

The reliable, quick and simple methods are needed for properly estimating antioxidant capacity of TCB. Therefore, two most commonly used methods were used to investigate antioxidant activity of samples. Free radical scavenging potential of TCBs with different roasting degrees were evaluated using the methods of DPPH and FRAP are presented in Table 3. Findings pointed out that there is significant difference in the antioxidant activity at different roasting degrees $(p<0.05)$. In the DPPH assay, TCB3 sample exhibited the highest antioxidant activity $(65.59 \pm 0.41 \%)$, while the lowest antioxidant activity was determined in TCB8 (37.41 \pm $0.52 \%)$. In the FRAP assay, the lowest value (247.47 \pm $0.93 \mathrm{mg} \mathrm{FeSO}$ per $100 \mathrm{~mL}$ TCB) was noted for TCB5 and the highest value $\left(451.78 \pm 0.31 \mathrm{mg} \mathrm{FeSO}_{4}\right.$ per $100 \mathrm{~mL}$ TCB) was also observed for TCB7. In this study, it was determined that the radical scavenging activity of all TCBs, except dark roasted coffee brews, increased with the roasting process. Because the compounds occur the result of Maillard reaction exhibited antioxidant properties. These diminished the loss of the natural antioxidants and increasing the whole antioxidant properties of coffee brews ${ }^{72}$. Also, the isomerization of chlorogenic acid occurred and was partially converted to lactones. ${ }^{45,73,74}$ Chlorogenic acid lactones are compounds that had antioxidant activity. Dark roasted coffee brews (TCB4 and TCB8 samples) did not exhibit the highest antioxidant activities compared to other samples due to the fact that the highest concentration of the Maillard products had in medium roasted samples. ${ }^{75}$ Results obtained in this study agreed with those previously reported by several researchers. ${ }^{40,41,44,45,72,75}$

When the effect of adding sugar into TCBs on antioxidant activity determining with DPPH method was investigated, a significant difference between TCBs with sugar and with no sugar was obtained $(p<0.05)$. The radical scavenging activities of TCBs with sugar were found to be lesser compared to TCBs without sugar. Due to the water content of TCBs, polyphenols of coffee were degraded. ${ }^{70,71}$ Because of this reason, the measured antioxidant activity was also decreased. In contrast to the DPPH method, there was not a significant effect of adding sugar into the TCBs on antioxidant activity determining with the FRAP method ( $p>0.05)$. Although the mechanism that relates to antioxidant activity is an electron transfer in both methods (DPPH and FRAP methods), FRAP cannot detect compounds 


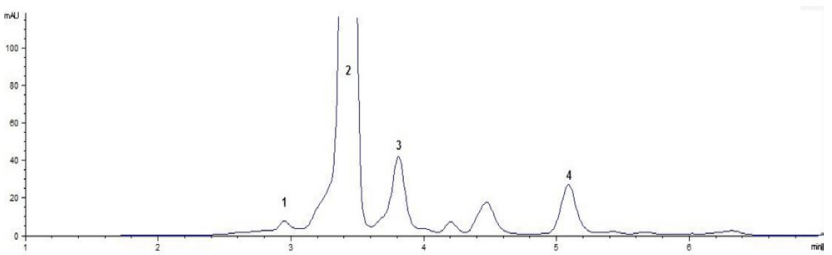

Figure 2: HPLC chromatogram of TCB2 sample. Peaks: 1, chlorogenic acid; 2, caffeine; 3, caffeic acid; 4, sinapic acid.

that act by radical quenching ( $\mathrm{H}$ transfer), particularly thiols and proteins. ${ }^{76,77}$ These situations caused difference between results obtained by DPPH and FRAP methods. It is known that FRAP values had a poor relationship to other antioxidant activity methods. ${ }^{76}$

\section{The Phenolic Compounds and Caffeine Determining by HPLC in TCBs}

According to the results of HPLC analysis, three phenolic compounds and caffeine was quantified (Figure 2). Sinapic acid displayed the highest amount in overall coffee brews, followed by caffeic acid and chlorogenic acid, generally. All of the phenolic compounds and caffeine presented different amounts in TCBs with different roasting degrees, depending on the initial concentration of them in green coffee and roasting process conditions. They were degraded partly or completely during the roasting process.

The data obtained from HPLC analysis were presented in Table 3. Significant differences were detected between individual polyphenol and caffeine concentrations of TCBs had different degree of roast $(\phi<0.05)$. The amount of whole phenolic compounds and caffeine determined in Turkish-style coffee brews, except chlorogenic acid, decreased with roasting process and increased with roasting degree, even caffeic asit degraded completely in dark roasted coffee. Only, the amount of chlorogenic acid and caffeine increased slightly at the beginning of the roasting process and then it decreased with the increasing roasting degree. During intense roasting, phenolic acids content increased as a result of the thermal instability of them and finally degraded. For example, chlorogenic acid partly converts to their lactones with dehydration of chlorogenic acid and the formation of intramolecular bonds. ${ }^{45,73,74}$ Similar observations to this study in related with phenolic compounds change with roasting degree of coffee were reported by others as well..$^{41,45,63,78,79}$ Also, the roasting process reduced caffeine content of coffee. ${ }^{41,79}$ This observation about caffeine change in TCBs are in agreement with previous findings, which confirmed the roasting results with the change of caffeine amount by several reports. ${ }^{41,63,79}$

According to the results of Table 3, the sugar addition during the cooking process of the Turkish-style coffee brews was caused the decrease of the main phenolic compounds. A statistically significant decrease was found in the phenolic compounds, except sinapic acid, detected in the TCBs with sugar addition $(p<0.05)$. The amount of sinapic acid did not exhibit statistically significant change between TCBs with sugar or without sugar $(p<0.05)$. The reasons of these differences seem to be embedded in the degradation of chlorogenic acid, caffeic acid and caffeine depending on water content of TCBs on the sugar addition, whereas sinapic acid is stable against this type of degradation.

\section{Correlations Related with Results Obtained from Analyses}

According to Pearson correlation test, statistically significant correlations were found between $\mathrm{b}^{*}, \Delta \mathrm{E}^{*}$ values of TCBs and $h^{\circ}$ value of TCBs $(p<0.05)$. While statistically significant correlations were observed between caffeine content of TCBs and total flavonoid content of TCBs, statistically significant negative correlations were obtained between browning intensity of TCBs and total flavonoid content of TCBs $(p<0.05)$. Also, statistically significant correlations were determined between $h^{\circ}$ value, caffeine content of TCBs with antiradical activity by using DPPH method of TCBs $(p<0.05)$. Statistically significant negative correlations were obtained between $\mathrm{h}^{\circ}$ value, $\Delta \mathrm{E}^{*}$ value, and caffeine content of TCBs with antiradical activity by using FRAP method of TCBs $(p<0.05)$. Additionally, statistically significant correlations were found between antiradical activity by using DPPH method of TCBs and chlorogenic acid content of TCBs $(p<0.05)$. Statistically significant correlations were determined between $h^{\circ}$ value and caffeine content of TCBs with caffeic acid content of TCBs $(p<0.05)$. The negative correlations of between browning intensity of TCBs and sinapic acid content of TCBs were obtained as statistically significant $(\phi<0.05)$. While all of the obtained statistically significant correlations has been between 0.30 and 0.61 , statistically significant negative correlations has been between -0.54 and $-0.72(p<0.05)$. Whole correlations seemed as poor $(\phi<0.05)$. No statistically significant correlations were obtained among other analyses results of all coffee samples $(p<0.05)$. These correlations which confirm the conclusion obtained from the experimental data that the change of polyphenols, antioxidant activity, and color characteristics, are related with changing 


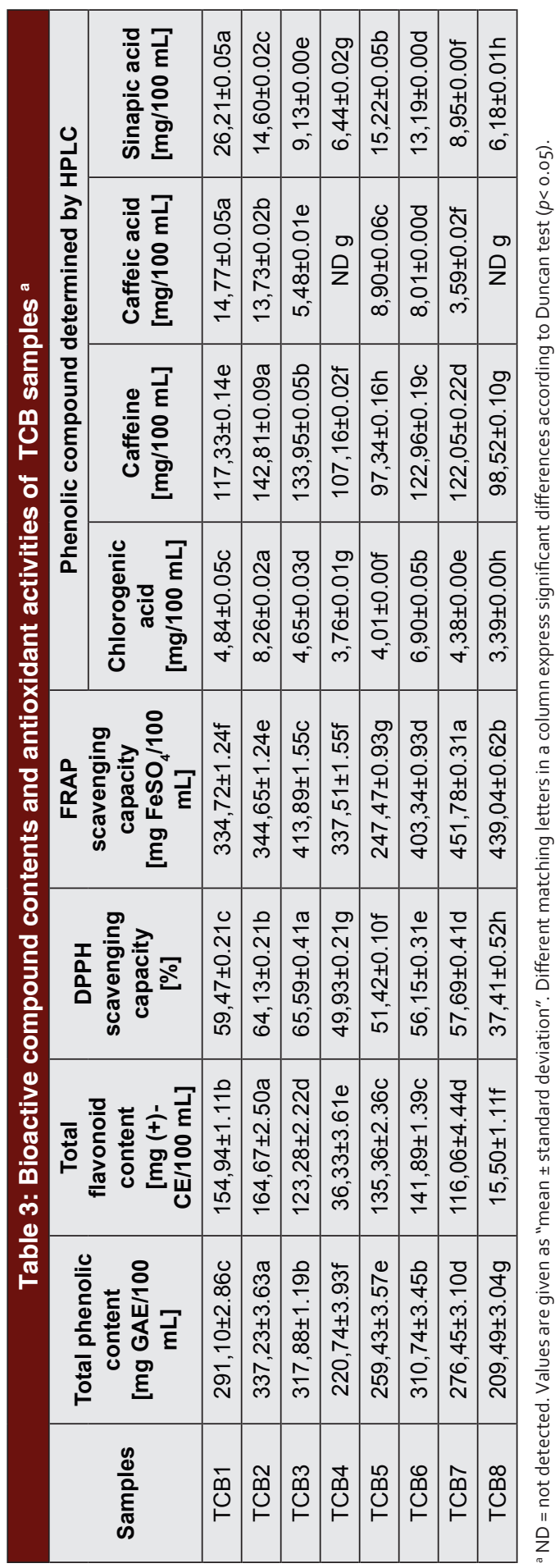

roasting degree of coffee and they are similar with some results found in the literature. ${ }^{45}$

According to correlation matrix based on the relations among the analyses results of TCBs with sugar and with no sugar; high correlations $(0.90-0.99)$ observed between the samples with sugar and without sugar, from the data obtained via the analysis of total polyphenol content, total flavonoid content, antiradical activity (by using DPPH method), the phenolic compounds and caffeine (determined by HPLC), $\mathrm{b}^{*}$ and $\mathrm{C}^{*}$ values, and browning intensity $(\mathrm{p}<0.05)$. While the lowest correlation is observed between the antiradical activities by using FRAP method of TCBs with sugar and with no sugar, correlations of $\mathrm{L}^{*}$ values, $\mathrm{a}^{*}$ values and $\Delta \mathrm{E}^{*}$ values are $0.77,0.78,0.89$, respectively $(p<0.05)$. Negative and poor correlation $(-0.50)$ is observed when $h^{*}$ value of TCB with sugar compared to $h^{*}$ value of one with no sugar $(p<0.05)$.

All of the observation indicates that the change in phenolic content, antioxidant activity and color properties of TCBs is more dependent on the roasting process than the addition of sugar.

This paper is about the determination of sugar addition effect on the polyphenol content and antioxidant activity of TCBs. Also, it meant to display double effects of roasting degree and sugar addition. There is also no study about the effect of sugar addition on coffee brew's phenolic compounds and antioxidant activities. Only, two studies have found on sugar addition. One of them is about sugar adding at roasting process ${ }^{42}$ and the other is about sugar addition in tea brew. ${ }^{69}$

\section{CONCLUSION}

Drinking coffee is an important indoor/outdoor social activity for many people. Turkish-style coffee brews which is traditionally prepared from Coffea arabica L. beans, also quite famous and consumed widely in the Balkan and Middle East countries. In this study, effects of sugar addition on the polyphenol content and antioxidant activity of TCBs were investigated in different degrees of roast TCBs for the first time. In the literature several studies have found related with the determination of polyphenol and antioxidant content of Turkish-style coffee brew. Both the phenolic content of TCBs and the effects of roasting degree and sugar addition on the phenolic compounds and antioxidant activity changes were determined in this study. Also, chromaticity parameters and browning intensities of TCBs were evaluated with changing roasting degree and sugar addition. Actually, TCBs are rich polyphenolic extracts which their antioxidant and phenolic compounds were 
extracted with hot water. Because they are made by boiling in water and their coffee grounds (telve) are not consumed. For this reason, they had been analyzed without applying to an extra extraction method. Generally, TCBs from different roasting degrees exhibited notable phenolic content and antioxidant potential, which were influenced by the roasting degree and the addition of sugar into it. The phenolic compounds, which present in Turkish-style coffee brew, are partly destroyed by the roasting process and other antioxidant compounds, like melanoidins, can be formed. So, antioxidant activity of TCBs can increase and phenolic content of TCBs can decrease due to the degree of roasting process. If the degree of roast increases continuously, destruction of the phenolic compounds cannot be possible to compensate the formation of other compounds after a certain stage. According to result of analysis, light roasted TCBs show greater polyphenol content while medium roasted TCBs show greater antioxidant capacity compared to other samples. Phenolic compounds are essential dietary components for human health, and the obtained data in this study show that TCBs have phenolic compounds with potential antioxidant activity. In addition, TCBs should be consumed without sugar to benefit from their health-promoting activities in maximum rate.

\section{CONFLCIT OF INTEREST}

The authors declare no conflict of interest.

\section{ABBREVIATIONS}

LC: liquid chromatography.

\section{REFERENCES}

1. Kuriyama S, Shimazu T, Ohmori K, Kikuchi N, Nakaya N, Nishino Y, et al. Green tea consumption and mortality due to cardiovascular disease, cancer, and all causes in Japan: The Ohsaki study. JAMA- Latest Med Res Rev Guidel. 2006;296(10):1255-65.

2. Hu G, Bidel S, Jousilahti P, Antikainen R, Tuomilehto J. Coffee and tea consumption and the risk of Parkinson's disease. Mov Disord. 2007;22(15):2242-8.

3. Eskelinen $\mathrm{MH}, \mathrm{Ngandu} \mathrm{T}$, Tuomilehto $\mathrm{J}$, Soininen $\mathrm{H}$, Kivipelto M. Midlife coffee and tea drinking and the risk of late-life dementia: A population-based CAIDE study. J Alzheimer's Dis. 2009;16(1):85-91.

4. Iso H, Date $\mathrm{C}$, Wakai K, Fukui M, Tamakoshi A, Mori M, et al. The relationship between green tea and total caffeine intake and risk for self-reported type 2 diabetes among Japanese adults. Ann Intern Med. 2006;144(8):554-62.

5. Odegaard AO, Pereira MA, Koh WP, Arakawa K, Lee HP, Yu MC. Coffee, tea, and incident type 2 diabetes: The Singapore Chinese Health Study. Am J Clin Nutr. 2008;88(4):979-85

6. Van Dam RM. Coffee consumption and risk of type 2 diabetes, cardiovascular diseases, and cancer. Appl Physiol Nutr Metab. 2008;33(6):1269-83.

7. Thielecke $F$, Boschmann M. The potential role of green tea catechins in the prevention of the metabolic syndrome - A review. Phytochemistry. 2009;70(1):11-24.
8. Nichenametla SN, Taruscio TG, Barney DL, Exon JH. A review of the effects and mechanisms of polyphenolics in cancer. J Crit Rev Food Sci Nutr. 2006;46(2):161-83.

9. Sun CL, Yuan JM, Koh WP, Yu MC. Green tea, black tea and breast cancer risk: A meta-analysis of epidemiological studies. Carcinogenesis. 2006;27(7):1310-5.

10. Ogunleye AA, Xue F, Michels KB. Green tea consumption and breast cancer risk or recurrence: a meta-analysis. Breast Cancer Res Treat. 2010;119(2):477-84.

11. Ferruzzi MG. The influence of beverage composition on delivery of phenolic compounds from coffee and tea. Physiol Behav. 2010;100(1):33-41.

12. Fardet A. New hypotheses for the health-protective mechanisms of wholegrain cereals: What is beyond fibre? Nutr Res Rev. 2010;23(1):65-134.

13. Wang $\mathrm{T}, \mathrm{He} \mathrm{F}$, Chen $\mathrm{G}$. Improving bioaccessibility and bioavailability of phenolic compounds in cereal grains through processing technologies: A concise review. J Funct Foods. 2014;7(1):101-11.

14. Huang HM, Johanning GL, O'Dell BL. Phenolic acid content of food plants and possible nutritional implications. J Agric Food Chem. 1986;34(1):48-51.

15. Peleg $\mathrm{H}$, Naim M, Rouseff RL, Zehavi U. Distribution of bound and free phenolic acids in oranges (Citrus sinensis) and grapefruits (Citrus paradisi). J Sci Food Agric. 1991;57(3):417-26.

16. Salunkhe, D. K.; Chaven, J. K.; Kadam SS. Plant phenolics: structure, classification, and biosynthesis. In: Salunkhe, D. K., Chaen JK, Kadam SS, editors. Dietary tannins : consequences and remedies. Boca Raton, FL: CRC Press; 1990. p. 5-28.

17. Shahidi F, Naczk M. Food phenolics: Sources, chemistry, effects, applications. Basel : Technomic Publishing Company. Lancaste, PA, USA; 1995. 331 p.

18. Macheix J-J, Fleuriet A, Billot J. Fruit phenolics. Boca Raton, Florida, USA: CRC Press, Inc; 1990. 378 p.

19. Herrmann K. Occurrence and content of hydroxycinnamic and hydroxybenzoic acid compounds in foods. Crit Rev Food Sci Nutr. 1989;28(4):315-47.

20. Nardini M, Cirillo E, Natella F, Scaccini C. Absorption of phenolic acids in humans after coffee consumption. J Agric Food Chem. 2002;50(20):5735-41.

21. Farah A, Donangelo CM. Phenolic compounds in coffee. Brazilian J Plant Physiol. 2006;18(1):23-36.

22. Shan J, Fu J, Zhao Z, Kong X, Huang H, Luo L, et al. Chlorogenic acid inhibits lipopolysaccharide-induced cyclooxygenase-2 expression in RAW264.7 cells through suppressing NF-KB and JNK/AP-1 activation. Int Immunopharmacol. 2009;9(9):1042-8.

23. Mussatto SI, Ballesteros LF, Martins S, Teixeira JA. Extraction of antioxidant phenolic compounds from spent coffee grounds. Sep Purif Technol. 2011;83(1):173-9.

24. Ashihara $\mathrm{H}$, Crozier $\mathrm{A}$. Caffeine: a well known but little mentioned compound in plant science. Trends Plant Sci. 2001;6(9):407-13.

25. Rostagno MA, Manchón $N$, D’Arrigo $M$, Guillamón $E$, Villares $A$, García-Lafuente A, et al. Fast and simultaneous determination of phenolic compounds and caffeine in teas, mate, instant coffee, soft drink and energetic drink by high-performance liquid chromatography using a fused-core column. Anal Chim Acta. 2011;685(2):204-11.

26. Njoroge JM, Agwanda CO, Kingori PN, Karanja AM, Gathaara MP. Coffee. In: Chopra, V.L., Peter KV, editor. Handbook of Industrial Crops (Crop Science). New York, USA: The Haworth Press; 2005. p. 295-333.

27. Zuorro A, Lavecchia R. Spent coffee grounds as a valuable source of phenolic compounds and bioenergy. J Clean Prod. 2012;34:49-56.

28. ICO. Total production by all exporting countries-Coffee. 2016 [cited $2016 \mathrm{Nov}$ 17]; Available from: http://www.ico.org/prices/po-production.pdf

29. Rodriguez MM, Marqués MAT, Sanchez-Muniz FJ. Consumo de café y colesterol sérico. Grasas y aceites. 1999;50(2):141-152.

30. Yilmaz PK, Hacibekiroğlu I, Kolak U. Effect of roasting on antioxidant and anticholinesterase capacities of coffee. J Food Nutr Res. 2014;53(3):232-9.

31. Wintgens JN. Coffee: growing, processing, sustainable production: a guidebook for growers, processors, traders, and researchers. Wiley-VCH Verlag GmbH and Co.; 2012. 983 p.

32. Bertrand B, Guyot B, Anthony F, Lashermes P. Impact of the Coffea canephora gene introgression on beverage quality of $C$. arabica $\mathrm{L}$. Theor Appl Genet. 2003;107(3):387-94.

33. Clarke RJ, Vitzthum OG. Coffee : recent developments. Blackwell Science; 2001. 257 p. 
34. Özdestan Ö. Evaluation of bioactive amine and mineral levels in Turkish coffee. Food Res Int. 2014;61:167-75.

35. Clarke RJ. Roasting and grinding. In: Clarke, R.J., Macrae R, editor. Coffee. Vol.2: Tec. Dordrecht: Springer Netherlands; 1987. p. 73-107.

36. Franca AS, Oliveira LS, Oliveira RCS, Agresti PCM, Augusti R. A preliminary evaluation of the effect of processing temperature on coffee roasting degree assessment. J Food Eng. 2009;92(3):345-52.

37. Kucukkomur S, Ozgen L. Coffee and Turkish Coffee culture. Pakistan J Nutr. 2009 Oct 1;8(10):1693-700.

38. Erdem SA, Senol FS, Budakoglu E, Orhan IE, Sener B. Exploring in vitro neurobiological effects and high-pressure liquid chromatography-assisted quantitation of chlorogenic acid in 18 Turkish coffee brands. J Food Drug Anal. 2016;24(1):112-20.

39. Bita MG, Preda M. The effect of temperature and roasting degree on the total phenolic content of coffee brews. Sci Study Res. 2005;VI(2):239-42.

40. Sacchetti G, Di Mattia C, Pittia P, Mastrocola D. Effect of roasting degree, equivalent thermal effect and coffee type on the radical scavenging activity of coffee brews and their phenolic fraction. J Food Eng. 2009;90(1):74-80.

41. Hečimović I, Belščak-Cvitanović A, Horžić D, Komes D. Comparative study of polyphenols and caffeine in different coffee varieties affected by the degree of roasting. Food Chem. 2011;129(3):991-1000.

42. Ludwig IA, Bravo J, De Peña MP, Cid C. Effect of sugar addition (torrefacto) during roasting process on antioxidant capacity and phenolics of coffee. LWT - Food Sci Technol. 2013;51(2):553-9.

43. Vignoli JA, Viegas MC, Bassoli DG, Benassi M de T. Roasting process affects differently the bioactive compounds and the antioxidant activity of arabica and robusta coffees. Food Res Int. 2014;61:279-85.

44. Priftis A, Stagos D, Konstantinopoulos K, Tsitsimpikou C, Spandidos DA, Tsatsakis AM, et al. Comparison of antioxidant activity between green and roasted coffee beans using molecular methods. Mol Med Rep. 2015;12(5):7293-302.

45. Górnaś P, Dwiecki K, Siger A, Tomaszewska-Gras J, Michalak M, Polewski K. Contribution of phenolic acids isolated from green and roasted boiled-type coffee brews to total coffee antioxidant capacity. Eur Food Res Technol. 2016;242(5):641-53.

46. Singleton, V.L. and Rossi JA. Colorimetry of total phenolics with phosphomolybdic- phosphotungstic acid reagents. Am J Enol Vitic. 1965;16:144-153.

47. Li Y, Guo C, Yang J, Wei J, Xu J, Cheng S. Evaluation of antioxidant properties of pomegranate peel extract in comparison with pomegranate pulp extract. Food Chem. 2006;96(2):254-60.

48. Heimler D, Vignolini P, Dini MG, Romani A. Rapid tests to assess the antioxidant activity of Phaseolus vulgaris L. dry beans. J Agric Food Chem. 2005;53(8):3053-6.

49. Chu Y-H, Chang C-L, Hsu H-F. Flavonoid content of several vegetables and their antioxidant activity. J Sci Food Agric. 2000;80(5):561-6.

50. Cheung LM, Cheung PCK, Ooi VEC. Antioxidant activity and total phenolics of edible mushroom extracts. Food Chem. 2003;81(2):249-55.

51. Guo C, Yang J, Wei J, Li Y, Xu J, Jiang Y, et al. Antioxidant activities of peel, pulp and seed fractions of common fruits as determined by FRAP assay. Nutr Res. 2003;23(12):1719-26.

52. Xu JZ, Yeung SYV, Chang Q, Huang Y, Chen Z-Y. Comparison of antioxidant activity and bioavailability of tea epicatechins with their epimers. $\mathrm{Br} \mathrm{J}$ Nutr. 2004;91(6):873-81.

53. Belguidoum K, Amira-Guebailia H, Boulmokh Y, Houache O. HPLC coupled to UV-vis detection for quantitative determination of phenolic compounds and caffeine in different brands of coffee in the Algerian market. J Taiwan Inst Chem Eng. 2014;45(4):1314-20.

54. Duenãs M, Peez-Alonso J, Santos-Buelga C, Escribano-Bailo T. Anthocyanin composition in fig (Ficus carica L.). J Food Compos Anal. 2008;21:107-15.

55. Ludwig IA, Bravo J, De Peña MP, Cid C. Effect of sugar addition (torrefacto) during roasting process on antioxidant capacity and phenolics of coffee. LWT - Food Sci Technol. 2013;51(2):553-9.

56. Liang N, Xue W, Kennepohl P, Kitts DD. Interactions between major chlorogenic acid isomers and chemical changes in coffee brew that affect antioxidant activities. Food Chem. 2016;213:251-9.
57. Ajandouz EH, Puigserver A. Nonenzymatic browning reaction of essential amino acids: Effect of $\mathrm{pH}$ on caramelization and Maillard reaction kinetics. J Agric Food Chem. 1999;47(5):1786-93.

58. Fujioka K, Shibamoto T. Chlorogenic acid and caffeine contents in various commercial brewed coffees. Food Chem. 2008;106(1):217-21.

59. Liu Y, Kitts DD. Confirmation that the Maillard reaction is the principle contributor to the antioxidant capacity of coffee brews. Food Res Int. 2011;44(8):2418-24.

60. Hofmann T. Quantitative studies on the role of browning precursors in the Maillard reaction of pentoses and hexoses with I -alanine. Eur Food Res Technol. 1999;209(2):113-21.

61. Rizzi GP. Chemical structure of colored maillard reaction products. Food Rev Int. 1997;13(1):1-28.

62. Al-Wahab ZN. An evaluation of the effect of different drinks on the color change of composan ceram composite resin (in vitro study). Mustansiria Dent J. 2009;6(1):14-9.

63. Vignoli JA, Bassoli DG, Benassi MT. Antioxidant activity, polyphenols, caffeine and melanoidins in soluble coffee: The influence of processing conditions and raw material. Food Chem. 2011;124(3):863-8.

64. Cheong MW, Tong KH, Ong JJM, Liu SQ, Curran P, Yu B. Volatile composition and antioxidant capacity of Arabica coffee. Food Res Int. 2013;51(1):388-96.

65. Cämmerer B, Kroh LW. Antioxidant activity of coffee brews. Eur Food Res Technol. 2006;223(4):469-74.

66. Žilić S, Kocadağli T, Vančetović J, Gökmen V. Effects of baking conditions and dough formulations on phenolic compound stability, antioxidant capacity and color of cookies made from anthocyanin-rich corn flour. LWT - Food Sci Technol. 2016;65:597-603.

67. Scalbert A, Williamson G. Dietary intake and bioavailability of polyphenols. J Nutr. 2000;130(8S Suppl):2073S-85S.

68. Hudáková J, Marcinčáková D, Legáth J. Study of antioxidant effects of selected types of coffee. Folia Vet. 2016;60(3):34-38.

69. Sharma V, Vijay Kumar H, Jagan Mohan Rao L. Influence of milk and sugar on antioxidant potential of black tea. Food Res Int. 2008;41(2):124-9.

70. Lončarić A, Pichler A, Trtinjak I, Piližota V, Kopjar M. Phenolics and antioxidant activity of freeze-dried sour cherry puree with addition of disaccharides. LWT - Food Sci Technol. 2016;73:391-6.

71. Syamaladevi RM, Sablani SS, Tang J, Powers J, Swanson BG. Stability of anthocyanins in frozen and freeze-dried raspberries during long-term storage: in relation to glass transition. J Food Sci. 2011;76(6):414-21.

72. Nicoli MC, Anese M, Parpinel MT, Franceschi S, Lerici CR. Loss and/or formation of antioxidants during food processing and storage. Cancer Lett. 1997;114(1-2):71-4.

73. Clifford MN. Chlorogenic acids and other cinnamates-nature, occurrence, dietary burden, absorption and metabolism. J Sci Food Agric. 2000;80(7):1033-43.

74. Farah A, de Paulis T, Trugo LC, Martin PR. Effect of roasting on the formation of chlorogenic acid lactones in coffee. J Agric Food Chem. 2005;53(5):1505-13.

75. Castillo MD, Ames JM, Gordon MH. Analysis of antioxidant properties of coffee brews [Internet]. 2001 [cited 2016 Nov 11]. Available from: https:// cordis.europa.eu/pub/improving/docs/ws_castillo.pdf

76. Prior RL, Wu X, Schaich K. Standarized methods for the determination of antioxidant capacity and phenolics in foods and dietary supplements. J Agric Food Chem. 2005;53(10):4290-302.

77. Ou B, Huang D, Hampsch-Woodill M, Flanagan JA, Deemer EK. Analysis of antioxidant activities of common vegetables employing oxygen radical absorbance capacity (ORAC) and ferric reducing antioxidant power (FRAP) assays: A comparative study. J Agric Food Chem. 2002;50(11):3122-3128.

78. Stalmach A, Mullen W, Nagai C, Crozier A. On-line HPLC analysis of the antioxidant activity of phenolic compounds in brewed, paper-filtered coffee. Brazilian J Plant Physiol. 2006;18(1):253-62.

79. Wanyika HN, Gatebe EG, Gitu LM, Ngumba EK, Maritim CW. Determination of caffeine content of tea and instant coffee brands found in the Kenyan market. African J Food Sci. 2010;4(6):353-8. 


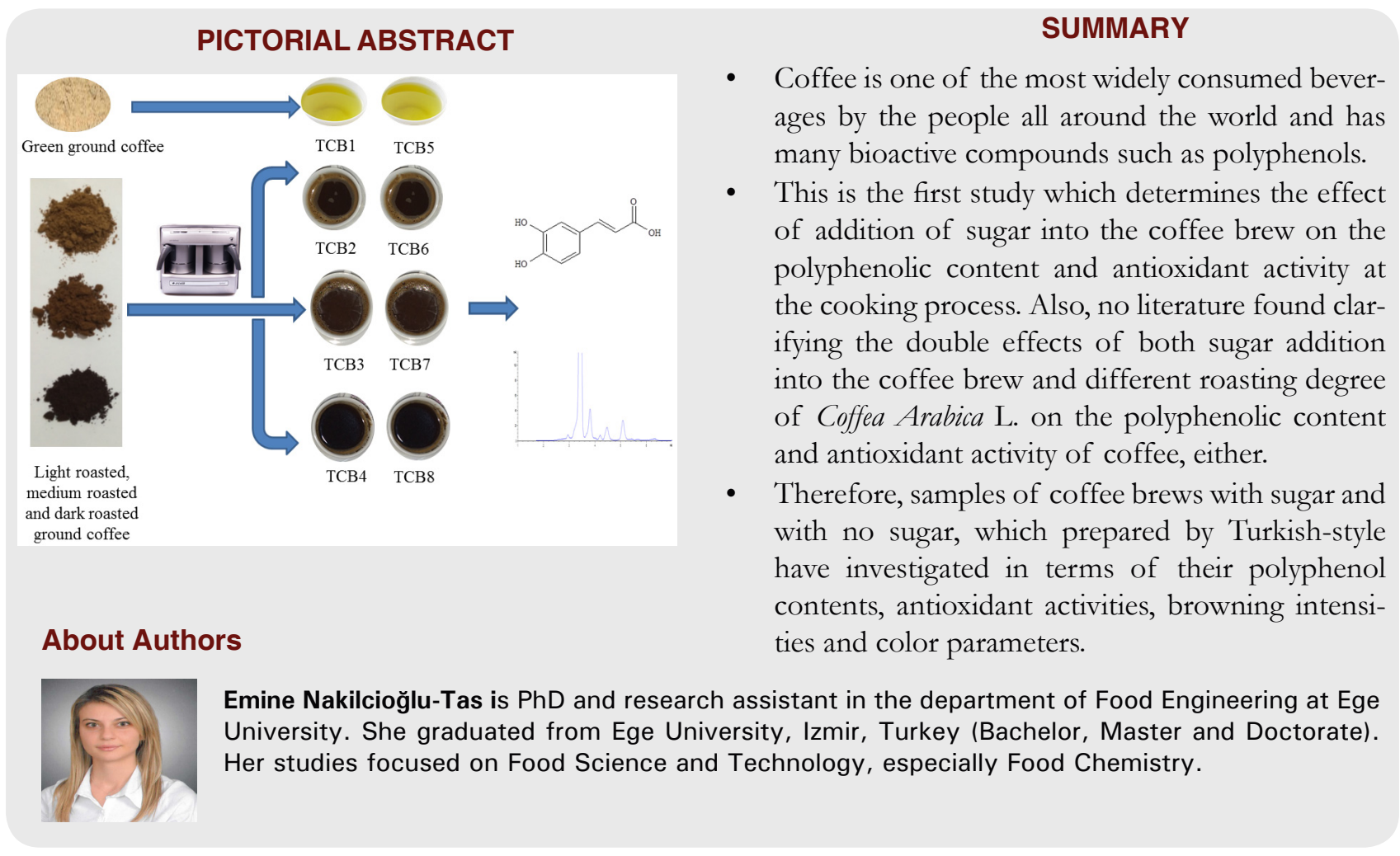

Cite this article: Tas-EN. The Effects of Sugar Addition and Degree of Roast on the Bioactive Compounds and Antioxidant Activity of Turkish-Style Coffee Brews. Indian J of Pharmaceutical Education and Research. 2018;52(3):456-66. 